\title{
Analysis and Design of Discrete-Sliding-Mode Control for a Square-Waveform-Ballast
}

\author{
R. Osorio, M. A. Oliver, M. Ponce, S. E. Pinto, M. Juárez, \\ R. Katebi ${ }^{1}$, MIEEE, M. J. Grimble ${ }^{1}$, F IEEE
}

\begin{abstract}
Analysis and design of a dimming control based on the Discrete Sliding Mode Control (DSMC) strategy for electronic ballasts (without resonant tank) is presented. To avoid the acoustic resonance phenomenon, the proposed scheme feeds the lamp with low frequency square waves, and then to stabilize the lamp current a dc-de converter with a closed loop control stage is included. For this purpose a Buck converter with DSMC control is used. A fast response and good reference pursuit is obtained, avoiding the lamp turn off or the lamp destruction when the dimming control is implemented. A reduction in electronic elements is achieved and the reliability of the overall system is incremented with the DSMC compared to the analog Sliding Mode control strategy. The analysis includes those conditions related to the existence of a sliding surface and the stability conditions. The simulations are made with a nonlinear dynamic lamp model. Analysis, simulation and experimental results of the proposed electronic ballast and the control stage are presented.
\end{abstract}

\section{INTRODUCTION}

The acoustic resonance phenomenon in HID lamps is the consequence of pressure waves of the filled gas inside the

Manuscript received March 7, 2005. This work was supported by the National Council of Science and Technology (CONACYT, México), the National Council for Technological Education (COSNET, México and Industrial Control Centre, University of Strathclyde (UK).

R. Osorio is with the Electronic Engineering Department in the National Center of Research and Technological Development (CENIDET), 62431, Cuernavaca, Morelos, México, Tel.: 01 (777) 318-7741, reneosorios@yahoo.com.

M. A. Oliver is with the Electronic Engineering Department in the National Center of Research and Technological Development (CENIDET), 62431, Cuernavaca, Morelos, México, Tel.: 01 (777) 318-7741, moliver@cenidet.edu.mx.

M. Ponce is with the Electronic engineering department in the National Center of Research and Technological Development (CENIDET), 62431, Cuernavaca, Morelos, México, Tel.: 01 (777) 318-7741, ponce@cenidet.edu.mx.

S. E. Pinto is with the Industrial Control Centre, University of Strathclyde, 50 Richmond St., Glasgow, UK and Engineering Department, Autonomous University of Tlaxcala Calzada Apizaquito S/N, ApizacoTlaxcala, Mexico. Tel: +44(0)1415484202, sepintocas@eee.strath.ac.uk.

M. Juárez is with the Electronic Engineering Department in the National Center of Research and Technological Development (CENIDET), 62431, Cuernavaca, Morelos, México, Tel.: 01 (777) 318-7741, MarioJb@hotmail.com.

${ }^{1} \mathrm{R}$. Katebi and M J Grimble are with the Industrial Control Centre, University of Strathclyde, 50 Richmond St., Glasgow, UK , r.katebi@eee.strath.ac.uk, m.grimble@eee.strath.ac.uk lamp. This phenomenon is caused by the lamp power modulation. The arc discharge is deformed by these pressure waves. Heating spots are generated when the glass bladder is reached by the arc, and generally these spots get broken [1].

One of the most reliable solutions for the elimination of the acoustic resonance phenomenon in HID lamps consists of feeding the lamp with square wave forms to reach a constant power. Most of the electronic ballasts that feed the lamps with square wave forms require a closed loop control stage to stabilize the lamp current $[2,3]$.

Generally, the discharge arc in HID lamps is extinguished if the power inferior limit is reached (approximately $50 \%$ of the nominal power) [4]. Therefore, to avoid the arc extinction, it is important that the dimming control of the electronic ballast has a good reference tracking. Additionally, it is important to have a good dynamic response in illuminating systems where voltage variations or load changes are likely to occur.

Good dynamic response, stability and regulation from voltage variations, may be achieved with the sliding mode control [5-6]. The HID lamp current is unstable when the lamp is fed with a voltage source, an example is a variable structure dc-dc converter working in continuous conduction mode (CCM). The control will drive the system to the balance point [5-6].

An igniter is needed when the HID lamps are fed with square waves. A proposed igniter is based on a resonant network; this network works only for $40 \mu \mathrm{s}-60 \mu \mathrm{s}$ in a high resonant frequency. Additionally, the semiconductor losses and the size of the passive elements are reduced.

An electronic ballast is presented in [7], feeding the HID lamp with low frequency square wave forms. The feedback control is designed with non linear sliding control. The control stage is implemented in analog form, and then many electronic elements (1 operational amplifier, 1 high speed comparator, 2 logic circuits, 13 resistors, 1 microcontroller) are needed.

This work proposed in this paper is to use a Discrete Sliding Mode Control for a non-resonant ballast. The following advantages are achieved against the Analog Sliding Mode Control [8]:

- Reduction in the number of electronic components, 
- Possibility of generating adaptive control to feed different lamps with the same electronic ballast.

- Flexibility in the creation of the sliding surface,

- The same control strategy is useful to different converters with minimum adjustment,

- Possibility of integrating advanced functions into the control algorithm, like digital compensators, etc.

The above advantages are in addition to those introduced by the sliding mode control.

The simulations of the electronic ballast with the nonlinear dynamic lamp model [9] were made in Simulink (SimPowerSystem and DSP libraries).

This paper is organized as follow: An analysis of the power stage of selected ballasts is made in section II. In section III an analysis of the control stage is made. An analysis of lamp model is made in section IV. In section V, simulations and experimental results are presented, and finally the conclusions are presented.

\section{Power StAGE}

The block diagram of the selected ballast is shown in figure 1. A buck converter is operating in CCM. This converter stabilizes the arc discharge and feeds the inverter. A dc bus is given by the dc-dc converter that integrates a power factor correction.

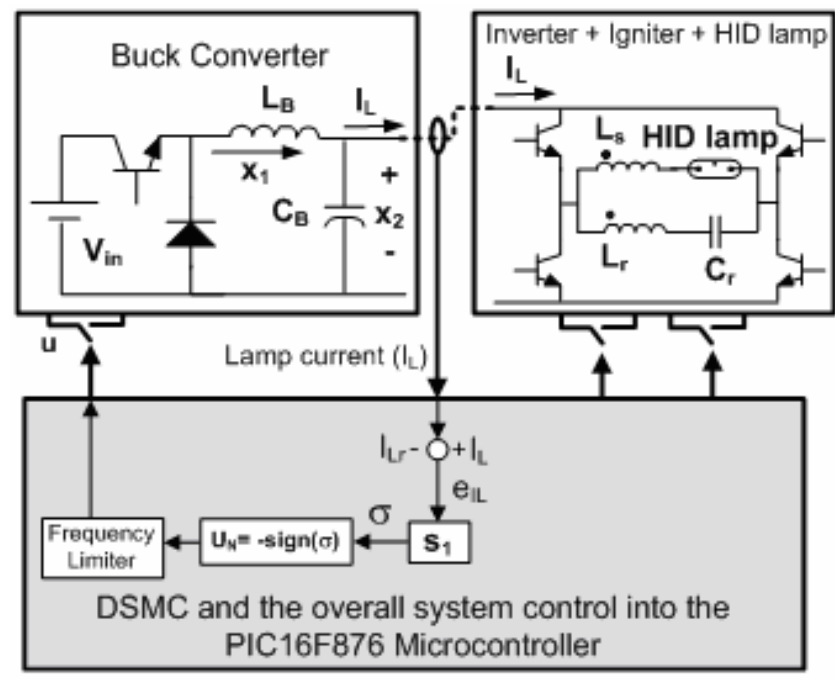

Fig. 1. Block diagram of selected topology with non linear control stage.

To avoid the acoustic resonance, the inverter feeds the HID lamp (70W metal Halide) with low frequency square waveforms $(400 \mathrm{~Hz}$, avoiding the effects of parasitic elements).

The igniter is conformed by the resonant network $\left(L_{r} C_{r}\right)$ in series configuration. $L_{r}$ is coupled to $L_{s}$ (autotransformer configuration). High voltages ( $4.5 \mathrm{kV}$ peak) can be reached with this configuration assuring the lamp ignition. The ignition sequence takes $40 \mu \mathrm{s}-60 \mu \mathrm{s}$ ( 4 or 6 pulses of 100
$\mathrm{kHz}$ ). The operating frequency of the inverter changes to $400 \mathrm{~Hz}$ when the lamp ignition is reached. Therefore, at this frequency, the inductor impedance is very low (short circuit) and the capacitor impedance is very high (open circuit) and both impedances can be ignored.

\section{CONTROL STAGE}

For DSMC design the following steps must be developed $[8,10]$ : System modeling, Sliding surface definition, Control law, Existence and convergence conditions of DSMC.

\section{System modeling}

The power stage (figure 2(a)) can be simplified as follows: The influence of the igniter on the ballast in stable state is small, (figure 2(b)). The inverter current demanded from the Buck converter is constant and can be eliminated (figure 2(c)). Finally the semiconductors can be substituted by ideal switches and the lamp is considered in stable state as a constant resistance only for the controller parameters calculations (figure 2(d)). In the simulations the lamp model proposed in $[8,11]$ is considered.

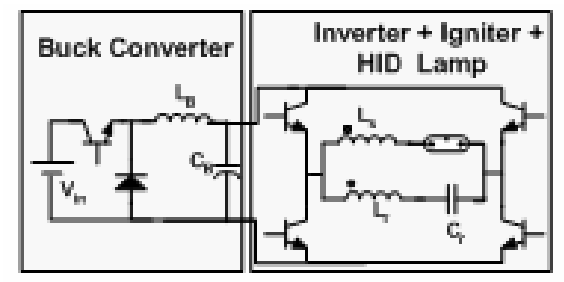

(a)
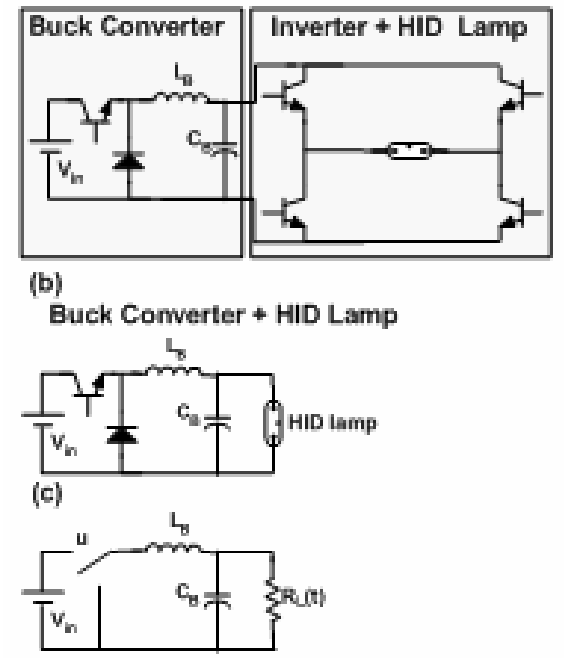

(d)

Fig. 2. Ballast simplifications: (a) complete power stage, (b) without igniter, (c) without inverter, (d) using ideal switch and considering the lamp as a resistance.

The resultant system in matrix form considering the position of the switch $u_{1}(1$ and -1$)$ is: 


$$
\left(\begin{array}{l}
\dot{x}_{1} \\
\dot{x}_{2}
\end{array}\right)=\left(\begin{array}{cc}
0 & -\frac{1}{L_{B}} \\
\frac{1}{C_{B}} & -\frac{1}{C_{B} R}
\end{array}\right)\left(\begin{array}{l}
x_{1} \\
x_{2}
\end{array}\right)+\left(\begin{array}{c}
\frac{V_{i n}}{2 L_{B}} \\
0
\end{array}\right) u+\left(\begin{array}{c}
\frac{V_{i n}}{2 L_{B}} \\
0
\end{array}\right)
$$

Or in matrix form:

$$
\dot{X}=A X+B U+B
$$

where: $\mathrm{x}_{1}$ is the $\mathrm{L}_{\mathrm{B}}$ inductor current, $\mathrm{x}_{2}$ is the $\mathrm{C}_{\mathrm{B}}$ capacitor voltage.

For $\mathrm{L}_{\mathrm{B}}=5 \mathrm{mH}, \mathrm{C}_{\mathrm{B}}=1 \mu \mathrm{F}, \mathrm{R}=115 \Omega, \mathrm{V}_{\mathrm{in}}=180 \mathrm{~V}$ :

$$
\left(\begin{array}{l}
\dot{x}_{1} \\
\dot{x}_{2}
\end{array}\right)=1 e 6\left(\begin{array}{ll}
0 & -0.0002 \\
1 & -0.0087
\end{array}\right)\left(\begin{array}{l}
x_{1} \\
x_{2}
\end{array}\right)+\left(\begin{array}{c}
18 e 3 \\
0
\end{array}\right) u+\left(\begin{array}{c}
18 e 3 \\
0
\end{array}\right)
$$

The discrete system using a zero-order hold, with a sampling period of $16 \mu$ s becomes:

$$
\begin{aligned}
\left(\begin{array}{l}
x_{1}(n+1) \\
x_{2}(n+1)
\end{array}\right)= & \left(\begin{array}{cc}
0.9757 & -0.002962 \\
14.81 & 0.8469
\end{array}\right)\left(\begin{array}{l}
x_{1}(n) \\
x_{2}(n)
\end{array}\right)+ \\
& +\left(\begin{array}{l}
0.5713 \\
2.1915
\end{array}\right) u(n)+\left(\begin{array}{l}
0.5713 \\
2.1915
\end{array}\right)
\end{aligned}
$$

The PIC16F876 microcontroller from the Microchip Company was used.

\section{The Sliding Surface}

The continuous-sliding surface proposed in [12] is a linear combination of the lamp current $\left(\mathrm{I}_{\mathrm{L}}\right)$ and the current reference $\left(\mathrm{I}_{\mathrm{Lr}}\right)$, figure 1:

$$
\sigma=s_{1}\left[I_{L}-I_{L r}\right],
$$

where: $\mathrm{s}_{1}$ is a parameter control.

Or well:

$$
\begin{array}{ll} 
& \sigma=\left[\begin{array}{ll}
s_{2} & s_{3}
\end{array}\right]\left[\begin{array}{c}
x_{1}-x_{1 r} \\
\frac{d x_{2}}{d t}-x_{2 r}
\end{array}\right], \\
\text { where } & s_{2}=s_{1} \\
: & s_{3}=s_{1} C_{B} \\
& x_{1 r} y x_{2 r} \text { are the reference } \\
\text { currents. }
\end{array}
$$

The discrete-sliding surface related to equation (6) is:

$\sigma(n)=S_{1}\left[I_{L}(n)-I_{L r}(n)\right]=\left[\begin{array}{ll}S_{2} & S_{3}\end{array}\right]\left[\begin{array}{c}x_{1}(n)-x_{1 r} \\ \frac{x_{2}(n+1)-x_{2}(n)}{T}-x_{2 r}\end{array}\right]$

Due to the operational amplifiers de Bus limitations, the $\mathrm{s}_{1}$ experimental value is chosen in the interval $(1,10)$, then the maximum value of $s_{3}$ is:

$$
s_{3}=s_{1} C_{B}=10 e-6 \ll s_{2}
$$

This implies:

$$
\sigma(n) \cong s_{1}\left[x_{1}(n)-x_{1 r}\right]
$$

where: $\mathrm{s}_{1}, \mathrm{~s}_{2}, \mathrm{~s}_{3}=$ controller parameters, $\mathrm{I}_{\mathrm{L}}=$ current lamp, $\mathrm{X}=$ state variables, $\mathrm{I}_{\mathrm{Lr}}, \mathrm{X}_{\mathrm{r}}=$ references.

The control law proposed is: $\mathrm{u}=\mathrm{u}_{\mathrm{eq}}+\mathrm{u}_{\mathrm{N}}$

Here: $\mathrm{u}_{\mathrm{eq}}=$ Equivalent control, $u_{N}=-\operatorname{sgn}(\sigma)$

\section{The control law:}

The law is [10]:

$$
u(n)=u_{e q}(n)+u_{N}(n)
$$

where: $u_{N}(n)=-\operatorname{sgn}(\sigma(n))$; implemented control,

$U_{e q}(n)$ is equivalent control. $U_{e q}(n)$ is included for analysis purposes, this implies a guarantee of the existence condition only locally.

The implemented control $\left(U_{N}(n)\right)$ does not include the equivalent control.

The existence and convergence conditions of DSMC

Equations (13) and (14) describe the existence of DSMC [10].

$$
(\sigma(n+1)+\sigma(n)) \operatorname{sign}(\sigma(n)) \geq 0, \text { convergence condition }
$$

$$
(\sigma(n+1)-\sigma(n)) \operatorname{sign}(\sigma(n))<0, \text { sliding condition }
$$

From experimental results, the lamp always ignites from these values: $x_{1}(n)=3 \mathrm{~A}$ (maximum value), $x_{2}(n)=20 V, x_{1 r}$ $=0.777 \mathrm{~A}$ and $\sigma>0$ when $\mathrm{u}_{\mathrm{n}}=-1$ :

$$
\begin{aligned}
& 4.31 s_{1} \geq 0, \text { convergence condition } \\
& -0.78 s_{1}<0, \text { sliding condition }
\end{aligned}
$$

$\mathrm{x}_{1}(\mathrm{n})=0.35 \mathrm{~A}$ (minimum value), $\mathrm{x}_{2}(\mathrm{n})=115 \mathrm{~V}, \mathrm{x}_{1 \mathrm{r}}=$ $0.777 \mathrm{~A}$ and $\sigma<0$ when $\mathrm{u}_{\mathrm{n}}=1$ :

$$
0.06 s_{1} \geq 0 \text {, convergence condition }
$$

$-0.13 s_{1}<0$, sliding condition

Then $s_{1}$ must be positive to satisfy equations (15) to (18).

\section{SIMULATION AND EXPERIMENTAL RESULTS}

The electronic ballast was designed with the following parameters: $\mathrm{P}_{\mathrm{o}}=70 \mathrm{~W}, \mathrm{~V}_{\text {in }}=180 \mathrm{Vdc}, \mathrm{V}_{\mathrm{C}}=90 \mathrm{Vdc}, \mathrm{I}_{\mathrm{L}}=$ 0.777A, $\mathrm{L}=5 \mathrm{mH}, \mathrm{C}=1 \mu \mathrm{F}, \mathrm{CDM} 70 \mathrm{~W} 830 \mathrm{PH}$ lamp, $\mathrm{s}_{1}=1$. The $\mathrm{C}$ and $\mathrm{L}$ values were designed according to current and voltage ripples.

In figure 3, the simulated circuit (Buck converter, DSMC and lamp model) is shown. Simulation results of the electronic ballast with DSMC control are shown in figures 4 and 5. In figure 4, the current demanded and the output voltage of the Buck converter are shown. In figure 5, a dimming test (from $100 \%$ to $50 \%$ ) is shown; this dimming is made with a change in the current reference. The demanded current and the output voltage to the Buck converter are shown. As it can be observed a good dynamic response is obtained. In these figures the effect of death times is shown. 


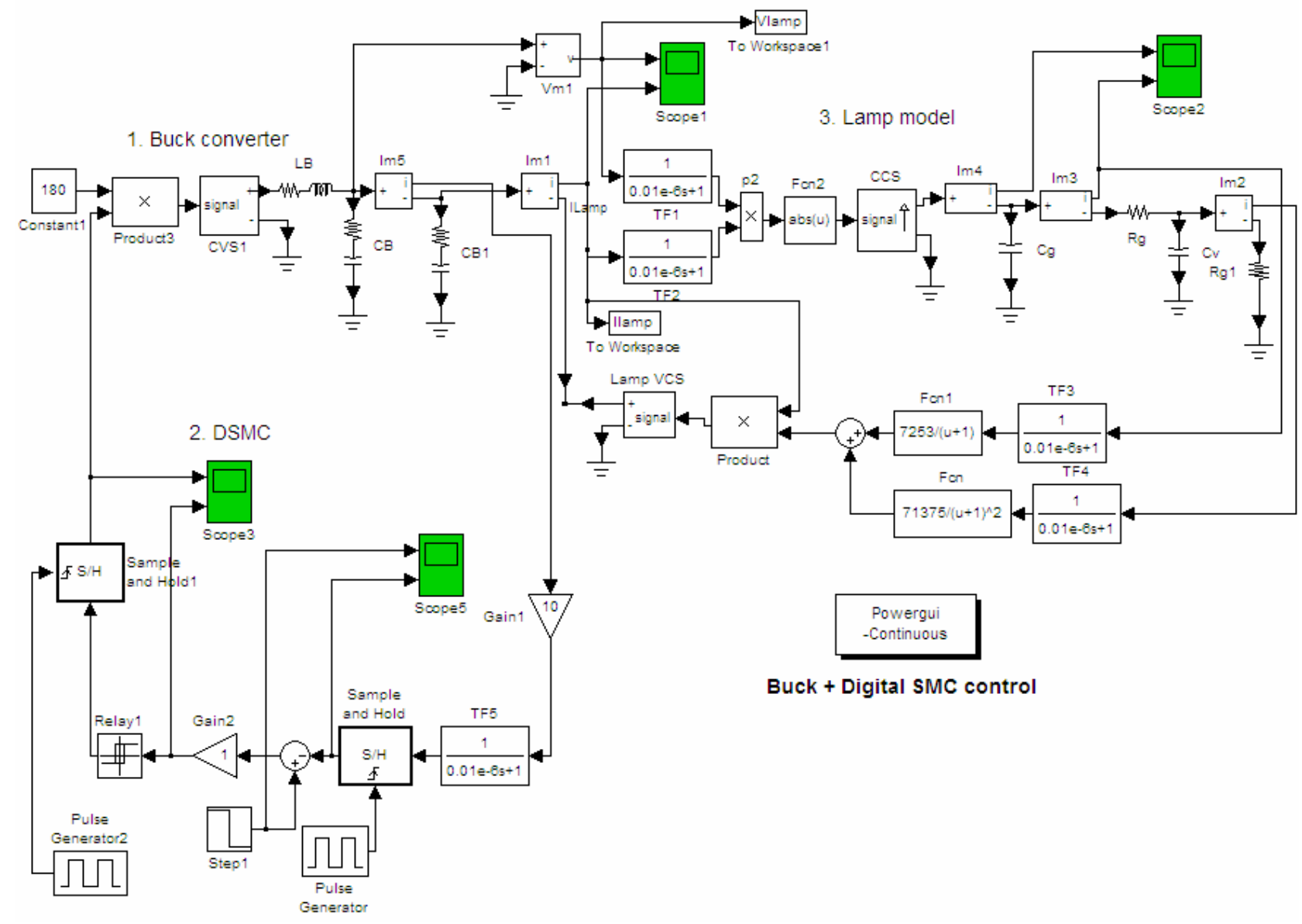

Fig. 3. Simulated scheme in Simulink.
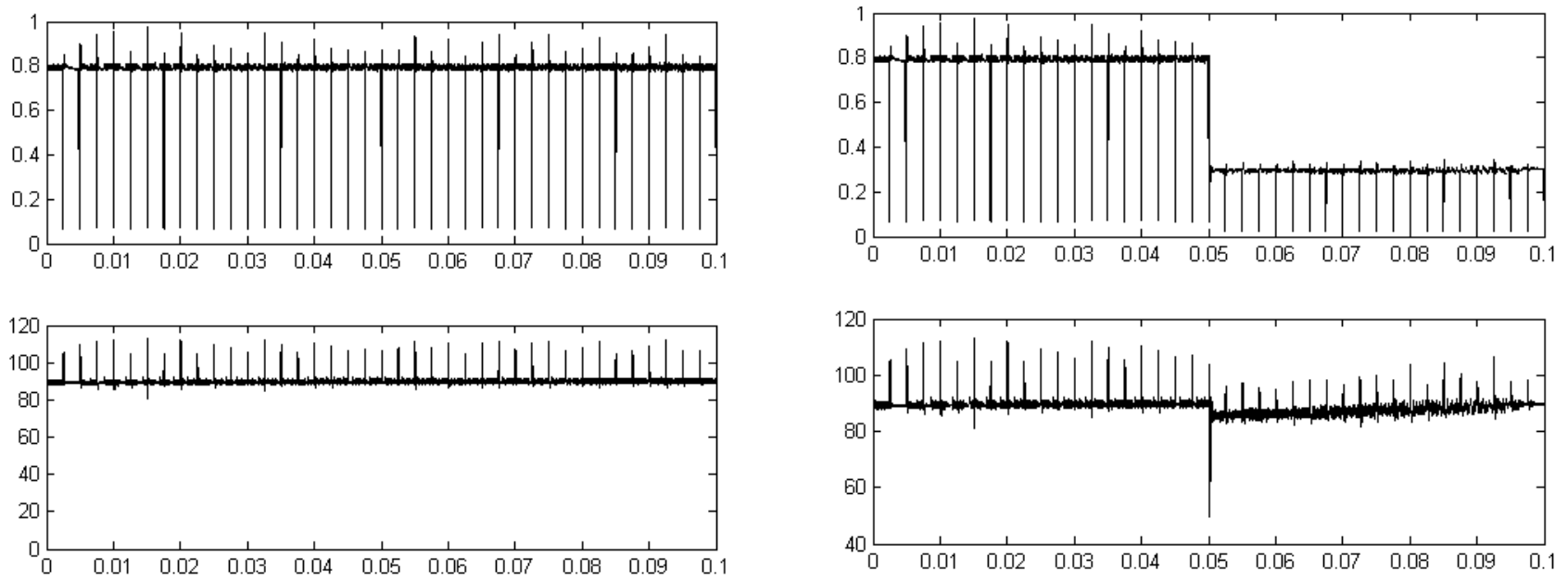

Fig. 4. Wave forms for nominal power (70W): (a) typical topology: current demanded (top) and output voltage of Buck Converter. (b) Compact topology: lamp current (top) and lamp voltage

Fig. 5. Dimming test (from $100 \%$ to $50 \%$ ), (a) typical topology: current demanded (top) and output voltage of Buck Converter. (b) Compact topology: lamp current (top) and lamp voltage (bottom). 


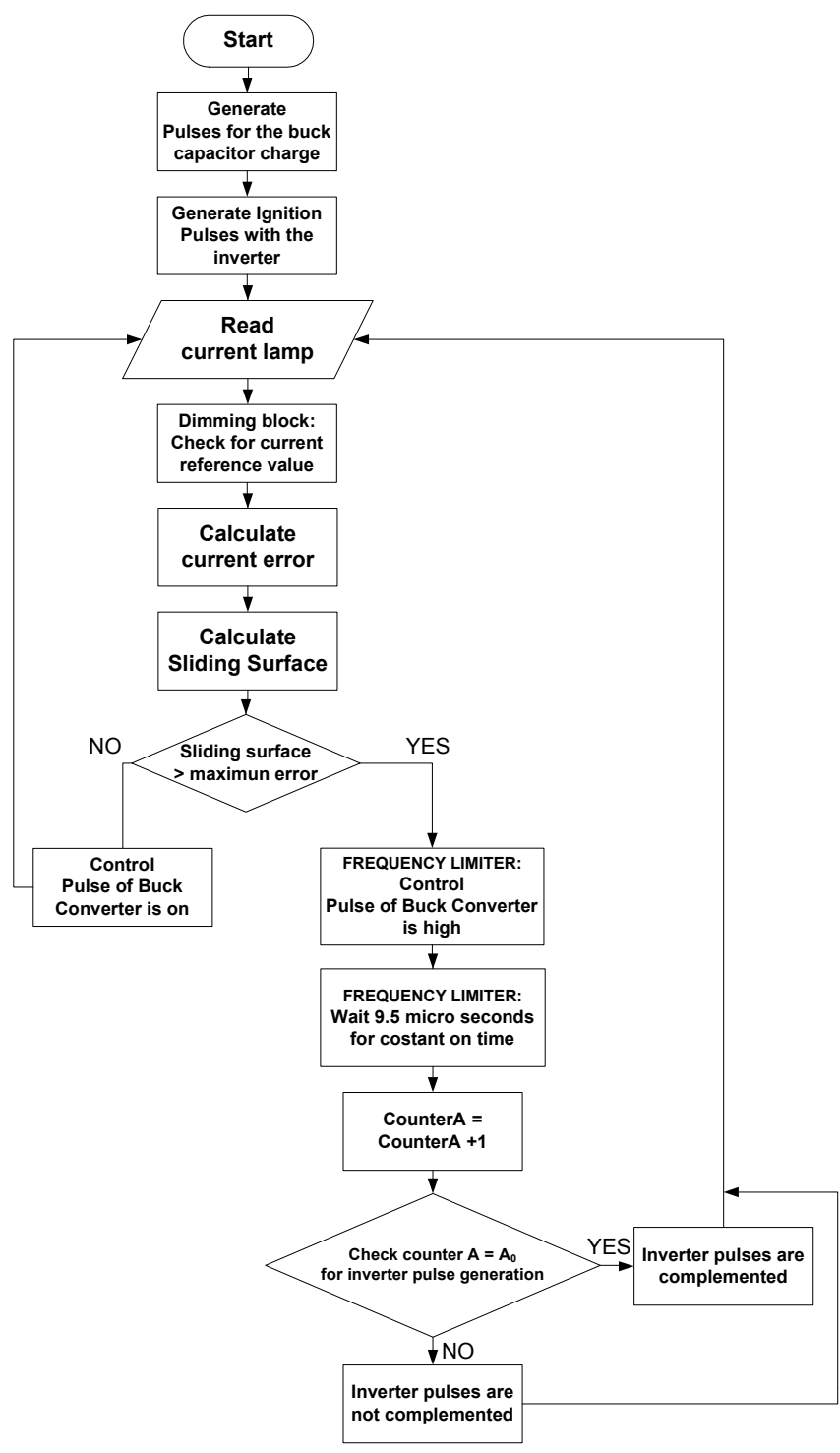

Fig. 6. DSMC program flux diagram implemented in the PIC16F876 microcontroller.

In figure 6, the DSMC program flux diagram is shown. Experimental results of the electronic ballast with DSMC control are shown in figures 7 and 8 . Figure 7, presents the experimental results of the electronic ballast with a SMC control under steady state condition. The current reference, lamp current and voltage are shown. In figure 8, a dimming test (from $100 \%$ to $50 \%$ ) is shown; this dimming is made with a change in the current reference. The current demanded and the output voltage of the Buck converter is shown. As it can be observed a good dynamic response is obtained.

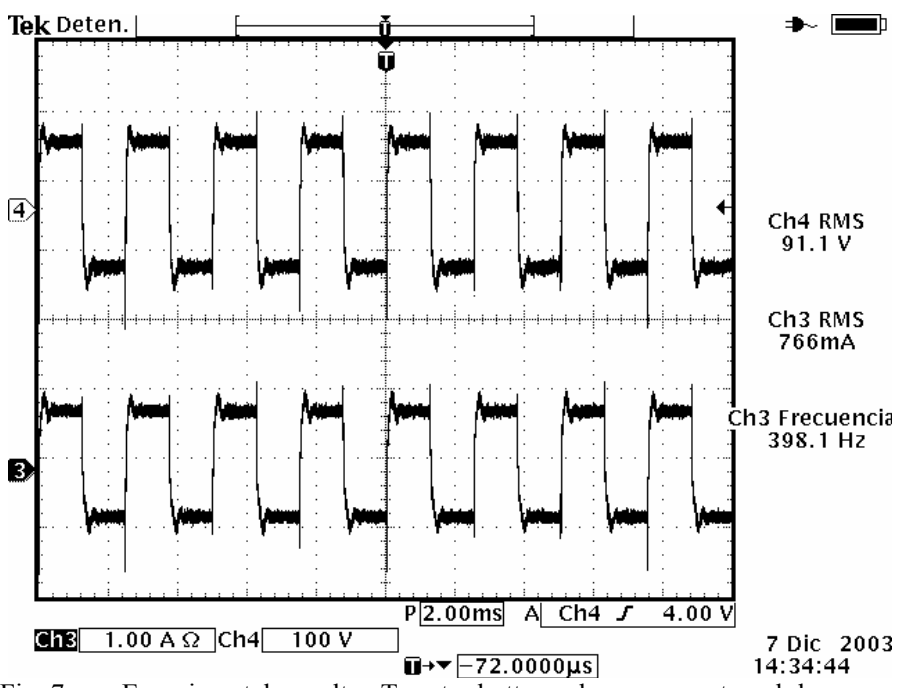

Fig. 7. Experimental results, Top to bottom: lamp current and lamp voltage.

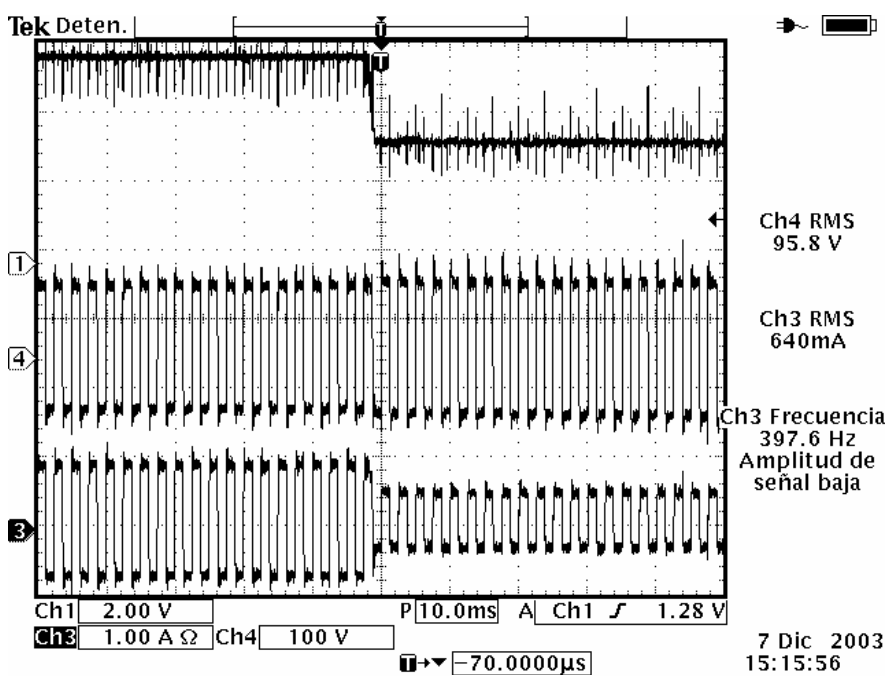

Fig. 8. Experimental results, dimming test (from $100 \%$ to $50 \%$ ), top to bottom: lamp current and lamp voltage.

\section{CONCLUSIONS}

In this paper an analysis of a HID lamp under the action of a discrete sliding mode non linear control (SMC) is presented. To avoid the appearance of acoustic resonance, the power stage feeds the HID lamp with low frequency square waves. A good dynamic response in dimming test is obtained because the control strategy is efficient. Also, the nonlinearity is considered in the buck model and the lamp model. This is other advantage of the nonlinear control strategy over the classic control strategy, because when a linearization model is obtained the analysis is limited to a region close to the operation point.

Also a dynamic nonlinear PSpice lamp model implementation in Simulink was shown.

The experimental results had shown a good behavior of the selected electronic ballast with a nonlinear control stage 
(SMC). Square waves are obtained with this topology and hence, the acoustic resonance phenomenon is eliminated.

\section{ACKNOWLEDGES}

This work was supported by the National Council of Science and Technology (CONACYT) and the National Council for Technological Education (COSNET), Mexico.

\section{REFERENCES}

[1] J. J. Groot and J. A. J. M. Van Vliet, "The high-pressure sodium lamp", Editorial Macmillan Education, 1986.

[2] E. Deng, "I. Negative incremental impedance of fluorescent lamp", Ph.D. Thesis, California Institute of Technology, Pasadena, 1995.

[3] E. Deng and S. Cuk, "Negative incremental impedance and stability of fluorescent lamp", Applied Power Electronic Conference, APEC'97, pp. $1050-1056$

[4] J. Correa, M. Ponce, J. Arau, J. M. Alonso, "Dimming in Metal-Halide and HPS Lamps operating al HF: Effects an Modeling", Industry Applications Conference, IAS'2002, pps: 1467-1474.

[5] V. I. Utkin, "Sliding Modes and Their Application in Variable Structure Systems", MIR Publishers, Moscow, 1974.

[6] Utkin, V., "Variable structure systems with sliding modes", Transactions on Automatic Control, 1977, pps: 212 -222.

[7] Ponce, M., Lopez, A., Correa, J.; Arau, J., Alonso, J.M., "Electronic ballast for HID lamps with high frequency square waveform to avoid acoustic resonances", Applied Power Electronics Conference and Exposition, APEC'2001,

pp: $658-663$ vol.2

[8] Orosco, R.; Vazquez, N.; "Discrete sliding mode control for DC/DC converters", Power Electronics International Congress, pp:231 - 236,

[9] R. Osorio, M. Ponce, M. A. Oliver, "Simplified Thermal-Electric Dynamic Model for HID lamps", Power Electronics Specialists Conference, PESC'04.

[10] Sarpturk, S.; Istefanopulos, Y.; Kaynak, O.; "On the stability of discrete-time sliding mode control systems", IEEE Transactions on Automatic Control, vol. 32, Oct 1987 pp: $930-932$.

[11] R. Osorio, M. Ponce, M. A. Oliver, "ANALYSIS AND DESIGN OF A DIMMING CONTROL USING SLIDING MODE CONTROL STRATEGY FOR ELECTRONIC BALLAST FREE OF ACOUSTIC RESONANCES", Applied Power Electronic Conference, APEC-04.

[12] R. Osorio, M. Ponce, M. A. Oliver, "Control por Modos Deslizantes en Corriente Aplicado a un Balastro Electrónico Libre de Resonancias Acústicas", Congreso Latinoamericano de Control Automático, CLCA'04. 